NEWS

\title{
Flu experts rebut conflict claims
}

Reports throw unsubstantiated suspicion on scientific advice given to the World Health Organization.

"Drug firms 'encouraged world health body to exaggerate swine flu threat," screamed Britain's Daily Mail newspaper on 4 June. "2 European reports criticize WHO's H1N1 pandemic guidelines as tainted," headlined The Washington Post the next day. To judge from media coverage last week, a major scandal had been exposed in the handling of the H1N1 flu pandemic by the World Health Organization (WHO). But nothing could be further from the truth.

The news articles reported on two investigations: one by journalists at the $B M J$ and the Bureau of Investigative Journalism, a non-profit body in London launched in April; the other by the health committee of the Parliamentary Assembly of the Council of Europe (PACE) - a human-rights body based in Strasbourg, France, independent of the European Union.

Both reports allege that the WHO might have been unduly influenced by the pharmaceutical industry in declaring $\mathrm{H} 1 \mathrm{~N} 1 \mathrm{flu}$ a pandemic, and in backing widespread vaccination and stockpiling of antiviral drugs, a claim often made by conspiracy theorists. They also complain that a 2004 WHO pandemic-preparedness document did not reveal that some of its authors had been paid for work by pharmaceutical companies although the scientists had declared their competing interests elsewhere.

\section{Suspicious minds}

Paul Flynn, a UK Labour Member of Parliament and rapporteur of the PACE report (see go.nature.com/G9CvVL), and Fiona Godlee, editor-in-chief of the $B M J$, presented their reports at a press conference together in Paris on 4 June, with Flynn asserting that "this was a pandemic that never really was". Afterwards, he wrote on his blog: "One of the joys today was giving evidence with the editor of the splendid British Medical Journal. We have never met before but we cooed in harmony and just avoided saying it was the Pharmas that did it."

Both reports say that it is suspicious, for example, that the WHO has kept secret the names of its Emergency Committee, an expert group that advises the $\mathrm{WHO}$ on the status of international public-health emergencies, including the declaration of a flu pandemic. Gregory Hartl, a spokesman for the WHO, says that the secrecy of the Emergency Committee's membership is maintained to buffer

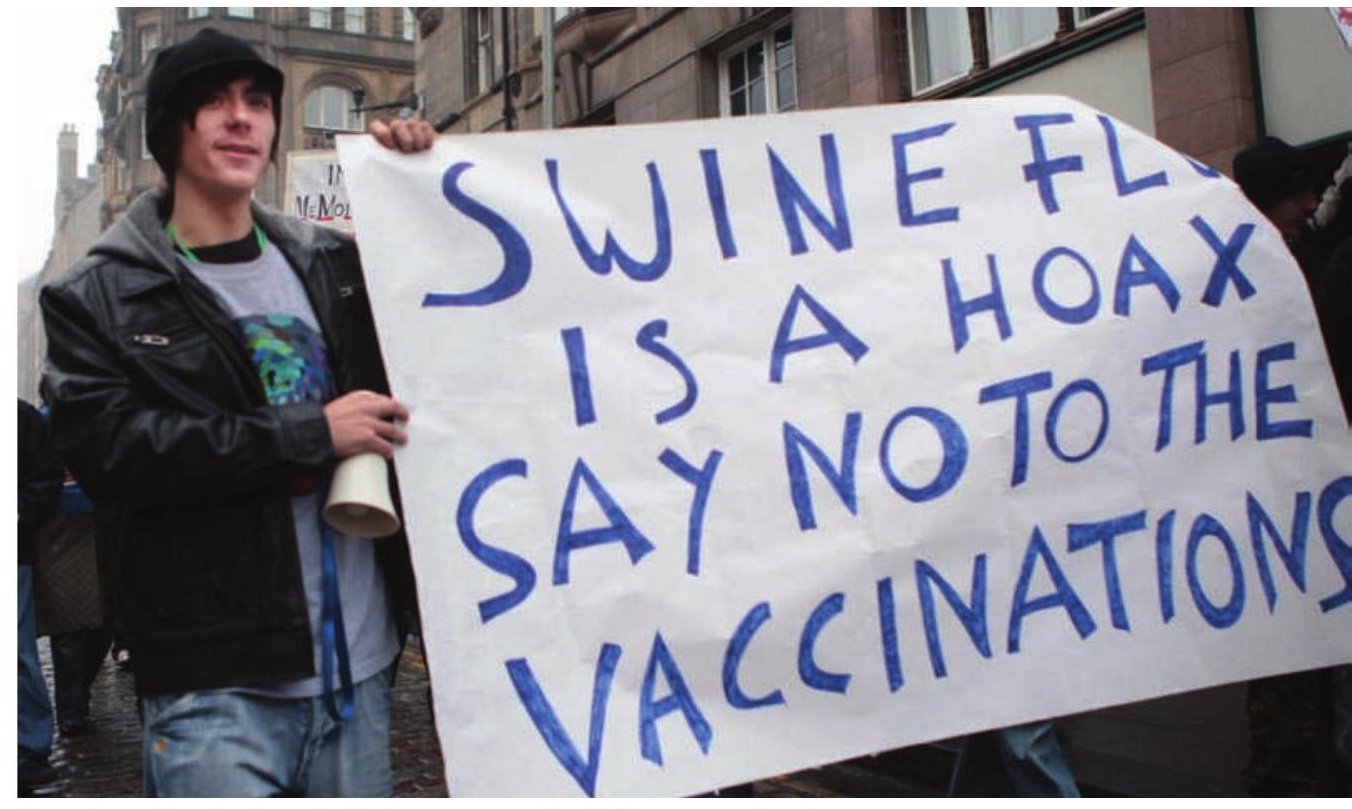

Conspiracy theories have fuelled protests against influenza vaccination.

its deliberations from outside pressure. The WHO says that it will make public the names, and any competing interests, once the pandemic is declared over.

"A key question will be whether the pharmaceutical companies, which had invested around $\$ 4$ bn ( $£ 2.8 \mathrm{bn}, € 3.3 \mathrm{bn})$ in developing the swine flu vaccine, had supporters inside the emergency committee, who then put pressure on WHO to declare a pandemic," says the article in the $B M J$ (D. Cohen and P. Carter Br. Med. J. 340, c2912; 2010). "It was the declaring of the pandemic that triggered the contracts."

This is false. Many countries - including the United Kingdom, France, Belgium, Finland, Canada, the Netherlands and Switzerland - had already placed large orders for H1N1 vaccine weeks before the WHO declared H1N1 a pandemic on 11 June 2009. The United States, for example, ordered US\$649 million of pandemic H1N1 influenza vaccine antigen and $\$ 283$ million of adjuvant on 22 May 2009. So the Emergency Committee could not have influenced these in any way.

"You are absolutely right," conceded the authors of the articles in the $B M J$ when challenged with this timeline.

Both reports also seize on the WHO's April 2009 revision of its criteria on what constitutes a pandemic, which removed the need for an assessment of the 'severity' of the disease, based on estimates of future mortality. Flynn speculated in the Daily Mail that this was suspicious: "In this case, it might not just be a conspiracy theory, it might be a very profitable conspiracy." Neither report provides any evidence to substantiate its implication that the WHO rushed to declare a pandemic to boost pharmaceutical company sales. Moreover, the WHO says that the revisions were finalized in February 2009, before pandemic H1N1 was on the horizon.

Scientists interviewed by Nature early on in the pandemic noted that severity is impossible to pin down until many months after it starts. Also, pandemic viruses can mutate or reassort to become more severe, so initial estimates are in any case of limited use.

\section{Clear firewall}

The $B M J$ also notes that three scientists who were involved in the preparation of a 2004 WHO document, WHO Guidelines on the Use of Vaccines and Antivirals during Influenza Pandemics, had received payments from pharmaceutical companies, including research funding, or consultancy or speaker fees. The scientists told the $B M J$ that they had declared these competing interests to the $\mathrm{WHO}$, although the WHO had not included these in its report.

Michael Osterholm, director of the University of Minnesota's Center for Infectious 
Disease Research and Policy in Minneapolis, points out that the 2004 document was based on input from an international panel of 22 scientists and public-health officials, in response to the threat of the deadly $\mathrm{H} 5 \mathrm{~N} 1$ avian flu virus. "To suggest that the three scientists were able to direct and control the final recommendations is naive, and stated without a single shred of evidence," he says.

The BMJ also claims that industry funding of the European Scientific Working Group on Influenza (ESWI), a group of flu scientists that provided advice to the WHO, presented a "potential conflict of interest". It notes that several ESWI scientists also receive industry funding directly.

One of those scientists is Albert Osterhaus, a virologist at Erasmus Medical Centre in Rotterdam in the Netherlands, who chairs the ESWI. He says that the body has a "clear firewall" with its funders, and that it informs all partners about any of its competing interests - its sources of funding are also listed on its website. Privatepublic partnerships are essential in tackling pandemics, and excluding flu researchers with industry links would deprive advisory panels of world-class expertise, he says. "The critical thing is transparency," says Osterhaus. "I have always declared my own competing interests."

The BMJ acknowledges that the researchers had declared their interests elsewhere. But it takes issue with the WHO's not having included them in its pandemic-planning documents.

David Ozonoff, an epidemiologist at the Boston University School of Public Health in Massachusetts, says that the reports "smear" the scientists involved in pandemic planning by "insinuating" that they would have offered different advice had they not had a relationship with drug companies. "This is a pretty serious charge," he says.

"We think this is the researcher's reading into it, not necessarily ours," the BMJ authors respond.

Marc Lipsitch, an epidemiologist at Harvard School of Public Health in Boston, Massachusetts, says that the WHO's advice on the pandemic has been sound, and has reflected the state of scientific opinion. Comparing the situation with the ongoing Deepwater Horizon oil spill, Lipsitch says that "it is ironic, as we watch for the second time in five years the catastrophic results of 'best-case scenario planning' in the Gulf of Mexico, to have the WHO coming under criticism for planning for, and raising awareness of, the possibility of a severe pandemic. That is what public-health agencies should do, and what most did in this instance, and they should be commended for it."

Declan Butler

\section{Engineer set to run NSF}

As an engineer, Subra Suresh has made a career of studying stress and fatigue: from aluminium alloys in planes and silicon wafers in chips, to the walls of cells infected with malaria. As the man nominated by Barack Obama's administration to head the US National Science Foundation (NSF), Suresh may soon find himself as challenged as the materials in his lab, as the agency competes for cash in an increasingly austere budget climate.

The 54-year-old dean of engineering at the Massachusetts Institute of Technology (MIT) in Cambridge, Suresh was named on 3 June to lead the \$6.9-billion NSF, which funds research in the non-medical sciences. If confirmed by the Senate, he would succeed nuclear engineer Arden Bement, who completed his six-year term at the end of May. Suresh - who would be the first Indian American to direct the NSF would take over just as a \$3-billion infusion of economic stimulus money given to the agency early last year begins to run out.

"Morale is going to be low," says Samuel Rankin, chair of the Coalition for National Science Funding, an advocacy group based in Washington DC. "He needs to take advantage of the fact that he's new and push for more funding."

Suresh studied mechanical engineering at the Indian Institute of Technology Madras in Chennai and received a doctorate from MIT in 1981. His research career has ranged widely, from the macroscopic study of alloys to the microscopic study of thin films such as those used in silicon chips. Now, he focuses on the biomechanics of diseased human cells. Colleagues say he has tried to foster such interdisciplinary work at MIT, and has boosted the number of researchers who hold joint appointments at two departments.

"Usually interdisciplinary means non-disciplinary," says Ben Freund, a mechanical engineer at Brown University in Providence, Rhode Island, who in 1983 recruited Suresh as an assistant professor there. "But he's truly made himself proficient in a number of areas and joined them in ways that have had an impact."

Ares Rosakis, who met Suresh as a graduate student at Brown, sees similarities between Suresh and another US agency head: Steven Chu at the Department of Energy. Like Chu, Rosakis says, Suresh is an academic shape-shifter who enthusiastically devours new topics. And, like $\mathrm{Chu}$, who directed the Lawrence Berkeley National Laboratory in California before he came to the capital, Suresh has maintained an active research lab after becoming an administrator. "You have to share some of the excitement of the process of research in order to actually implement the right changes," says Rosakis, now an aerospace and mechanical engineer at the California Institute of Technology in Pasadena.

In another parallel with $\mathrm{Chu}$, Suresh will arrive in Washington $\mathrm{DC}$ as a relative newcomer. "He may not have as much policy experience in Washington as some of his predecessors have had," says Eric Grimson, who works with Suresh as

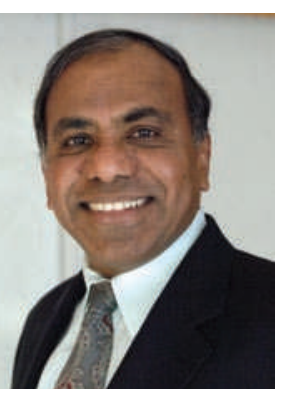

Subra Suresh is in line to head the US National cience Foundation. head of MIT's Department of Electrical Engineering and Computer Science. But Suresh has proved himself adroit at securing backing from fellow academics for endeavours such as revamping the engineering curriculum at MIT, his colleagues say. "I have no idea if his exposure to politics is enough," says Rosakis. "But academic politics can be very nasty too."

If confirmed, Suresh is likely to encounter politics in spades. The stimulus funding that was a windfall for the NSF last year came alongside a whopping $6.2 \%$ rise in regular agency funding for fiscal year 2010. As a result, the NSF made a record number of research grants, using stimulus funds to boost the acceptance rate for a backlog of qualified proposals. But that rate will drop as the stimulus money peters out, says Rankin.

Congress is unlikely to set the NSF's budget until after the midterm elections in November, which means funding could be frozen at 2010 levels well into next year. With concerns about the national debt rising, observers say that when Congress does act, the agency will be lucky to get half of the $8 \%$ budget increase that was requested by the White House in February. Eric Hand

r

